\title{
O significado de uma terapia integrativa de relaxamento guiado para mulheres com câncer de mama*
}

\author{
The meaning of integrative guided imagery relaxation therapy for women with breast cancer \\ El significado de una terapia integrativa de relajación guiada para mujeres con cáncer de mama
}

Como citar este artigo:

Toneti BF, Avelar JMP, Sousa FH, Toneti AN, Sonobe HM, Sawada NO. The meaning of integrative guided imagery relaxation therapy for women with breast cancer. Rev Esc Enferm USP. 2019;53:e03497. DOI: http://dx.doi.org/10.1590/S1980-220X2018024103497

\section{Bruna Francielle Toneti ${ }^{1}$ \\ Juliana Maria de Paula Avelar ${ }^{1}$ \\ Fernando Henrique Sousa ${ }^{1}$ \\ Adrielle Naiara Toneti ${ }^{1}$ \\ Helena Megumi Sonobe ${ }^{1}$ \\ Namie Okino Sawada ${ }^{1}$}

* Extraído do trabalho de Iniciação Científica "O significado do relaxamento com imaginação guiada para mulheres com câncer de mama",

Escola de Enfermagem de Ribeirão Preto,

Universidade de São Paulo, 2016.

${ }^{1}$ Escola de Enfermagem de Ribeirão

Preto, Universidade de São Paulo,

Ribeirão Preto, São Paulo, Brasil.

\begin{abstract}
Objective: Understanding the meaning of guided imagery relaxation for women with breast cancer, also investigating how patients view cancer and their immune system during guided imagery relaxation sessions and feel after it. Method: A qualitative study with a phenomenological approach and a Heideggerian theoretical-methodological reference based on the Creative and Sensitive Method, developed in the radiotherapy outpatient clinic of a public teaching hospital in the interior of São Paulo. The Heideggerian understanding was used for analyzing the data, which occurred in two stages: vague and medium understanding, and hermeneutics. Results: Nine women between the ages of 45 and 67 participated in the study. The data allowed us to understand the meaning of guided imagery relaxation from the participants, since they could be classified into three units of meaning: cancer stigma, facing disease and treatment benefits. Conclusion: The meaning of guided imagery relaxation made it possible to understand the being-in-theworld during the provided reflections, and it is possible to verify the importance of the nurse's offer of therapy in caring for women with breast cancer.
\end{abstract}

\section{DESCRIPTORS}

Breast Neoplasms; Relaxation Therapy; Complementary Therapies; Oncology Nursing; Women's Health. 


\section{INTRODUÇÃO}

O câncer é uma doença caracterizada pela proliferação celular anormal e desordenada, que pode acometer várias partes do corpo e, consequentemente, prejudicar sua capacidade funcional. As células mutadas e indiferenciadas são altamente capazes de se disseminar por outros tecidos, o que frequentemente se associa à maioria das mortes por câncer ${ }^{(1)}$. Com o processo de envelhecimento da população, o câncer vem se tornando um grande problema de saúde pública. Para o biênio 2018-2019, no Brasil, há estimativas da ocorrência de 600 mil novos casos de câncer para cada ano ${ }^{(2)}$.

Os tratamentos convencionais para o câncer podem ser feitos por meio de cirurgia, radioterapia, quimioterapia, tratamento hormonal e, em alguns tipos de câncer, também é utilizado o transplante de medula óssea, podendo haver a combinação de mais de uma dessas modalidades de tratamento. Contudo, os tratamentos convencionais estão frequentemente associados aos efeitos colaterais, que interferem significativamente na qualidade de vida dos pacientes e os levam a buscar recursos não farmacológicos que os auxiliem a controlar e prevenir tais sintomas ${ }^{(3)}$.

As terapias complementares são definidas como técnicas que não substituem os tratamentos convencionais (farmacológicos) prescritos, sendo utilizadas concomitantemente a eles com o intuito de aliviar os sintomas ou efeitos colaterais, como a redução da dor e fadiga, oferecendo conforto físico e psicológico ao paciente ${ }^{(3-5)}$. As terapias mente-corpo, em especial o relaxamento e a imaginação guiada, têm sido utilizadas como forma de auxiliar o paciente com câncer no alívio dos sintomas da doença e tratamento, sendo úteis para o enfrentamento e o processo de reabilitação do paciente ${ }^{(5-6)}$.

O relaxamento com imaginação guiada já é reconhecido pela sua eficácia e pelo efeito de profundo estado de relaxamento que proporciona, resultando na redução de alguns efeitos colaterais e permitindo, a cada desenvolvimento da prática, que o paciente se torne cada vez mais capaz de controlar seu próprio nível de relaxamento ${ }^{(6)}$. Além disso, a associação entre a terapia mente-corpo e o tratamento convencional do câncer possibilita que o paciente seja mais ativo à resposta ao combate à doença e direciona práticas do cuidado que intensificam o processo curativo.

A literatura sobre o assunto mostra que o sexo feminino com diagnóstico de câncer de mama, em especial, utiliza mais as terapias complementares do que o sexo masculino. $\mathrm{O}$ uso de tal prática também foi associado à idade, uma vez que adultos de meia-idade se mostraram mais adeptos ao uso das terapias complementares do tratamento oncológico, bem como os pacientes com grau de escolaridade mais elevado. Além disso, alguns sintomas do tratamento oncológico também se mostraram ligados às chances de o paciente envolver-se com a terapia nos estudos, como a dor, a insônia, a fadiga e a depressão $0^{(4-5)}$.

Estudos a respeito evidenciaram uma redução nos níveis avaliados de ansiedade e depressão de pacientes com câncer que utilizaram a terapia, bem como da pressão arterial sistólica e diastólica, frequência respiratória e cardíaca, mostrando que a realização de mais sessões de relaxamento com imaginação guiada teve um maior benefício ${ }^{(5-7)}$.

No Brasil, estabeleceu-se a Política Nacional de Práticas Integrativas e Complementares em 2006 com o intuito de atender às necessidades de pesquisa, apoio e incorporação das terapias complementares para o fortalecimento do Sistema Único de Saúde (SUS) e garantia da integralidade na atenção à saúde oferecida à população ${ }^{(8)}$. Recentemente, com a publicação da Portaria GM/MS n. ${ }^{\circ}$ 849/2017 e da Portaria n. ${ }^{\circ} 702 / 2018$, as práticas integrativas e complementares foram ampliadas quanto a sua oferta no SUS, totalizando 29 terapias disponíveis aos usuários do sistema, bem como o aumento da resolutividade em saúde no âmbito da atenção básica ${ }^{(9-10)}$.

Sabe-se, inclusive, que o cuidado de enfermagem ao paciente oncológico vem demandando cada vez mais conhecimentos que sustentem a prática clínica, sendo as terapias alternativas reconhecidas pelo Conselho Federal de Enfermagem na Resolução n. ${ }^{\circ}$ 0500/2015, como qualificação e/ou especialidade do enfermeiro, diante da conclusão e aprovação em cursos na área em instituições de ensino reconhecidas ${ }^{(11-12)}$.

O enfermeiro é um dos profissionais que mais pode oferecer informações acerca dos efeitos e benefícios do uso de terapias complementares ao tratamento oncológico, uma vez que ele possui contato direto e mais prolongado com o paciente durante o processo de tratamento e reabilitação da doença, o que oportuniza a ele prestar um cuidado mais centrado no sujeito e suas necessidades.

Embora haja alguns estudos na literatura que evidenciem os efeitos benéficos do relaxamento com imaginação guiada, ressalta-se que não há pesquisas na área que investiguem o significado dessa terapia, bem como sua relação com a adesão do paciente oncológico ao tratamento alternativo. Além disso, dado os efeitos biopsicossociais do câncer de mama, cada vez mais incidente em mulheres, compreender o significado do relaxamento com imaginação guiada para essa população pode fornecer importantes dados sobre a construção subjetiva dessa experiência.

Diante do exposto, este estudo foi desenvolvido com o objetivo de compreender o significado do relaxamento com imaginação guiada para mulheres com câncer de mama, buscando investigar, também, como as pacientes visualizam o câncer e seu sistema imunológico durante as sessões de relaxamento com imaginação guiada e se sentem após sua realização.

\section{MÉTODO}

\section{Desenho do estudo}

Trata-se de um estudo de natureza qualitativa, com abordagem fenomenológica e referencial teórico-metodológico heideggeriano, fundamentado no Método Criativo Sensível, com dinâmicas de criatividade e sensibilidade para investigação do significado do relaxamento com imaginação guiada para mulheres com câncer de mama. 
O referencial teórico-metodológico heideggeriano foi adotado por oferecer pressupostos filosóficos para a compreensão do homem por meio de seu discurso, pela experiência vivida e interpretação e elaboração dos conhecimentos, desvelando o fenômeno vivido em sua essência e os significados atribuídos pelo sujeito ${ }^{(13)}$.

O Método Criativo Sensível tem como bases teóricas o método de ensino crítico-reflexivo, que tem como pressuposto a pedagogia da criação coletiva e interativa de conhecimentos. As dinâmicas de criatividade e sensibilização das participantes têm como objetivo promover o contato destas com a sua subjetividade. "A criatividade e a sensibilidade são valorizadas na produção de dados de pesquisa, e as dinâmicas têm por objetivo facilitar a expressão das participantes da pesquisa" ${ }^{(14)}$. Além disso, os autores desses estudos afirmam que "combina ciência e arte ao aliar técnicas de coleta de dados já consolidadas na pesquisa qualitativa", como a entrevista e discussão grupal realizada no presente estudo, no qual o "propósito fundamental é aguçar a expressão da subjetividade das participantes da pesquisa"(14).

\section{Cenário}

Este estudo foi realizado em um ambulatório de radioterapia de um hospital de ensino público do interior paulista, no período de março a abril de 2016. As participantes foram convidadas na sala de espera do local, enquanto aguardavam pela sessão de radioterapia, havendo apenas três recusas de participação no estudo, que ocorreram devido à indisponibilidade de tempo das mulheres abordadas para a realização da sessão de relaxamento em grupo. A pesquisadora apresentou os objetivos do estudo para as participantes, bem como a sua relação com o grupo de pesquisa da área e instituição de atendimento.

\section{CRITÉRIOS DE SELEÇÃo}

Os critérios de inclusão adotados foram: mulheres maiores de 18 anos de idade, com diagnóstico de câncer de mama, iniciando tratamento radioterápico no local e recebendo a terapia de relaxamento com imaginação guiada. Foram excluídas pacientes que não conseguiam compreender as questões investigadas no presente estudo, avaliadas por perguntas simples, como data de nascimento, dia da semana e outras.

\section{Coleta de Dados}

A sessão de relaxamento com imaginação guiada foi realizada pela pesquisadora uma vez por grupo, conduzida por um $\mathrm{CD}$ de relaxamento com visualização guiada produzido pelo Centro de Apoio ao Paciente com Câncer de Florianópolis - SC, sendo este, inclusive, utilizado e validado por um estudo na área, que demonstrou a sua aplicabilidade e efetividade no alívio dos sintomas do tratamento oncológico ${ }^{(6)}$. Essa técnica de relaxamento utiliza a visualização de forma terapêutica e simbólica, estimulando zonas cerebrais responsáveis pela criação de imagens e sensação de bem-estar em seu praticante. Nela, exercícios de relaxamento muscular progressivo são conduzidos em associação à visualização de imagens, todos estes com objetivos clínicos de melhora do estado de saúde e qualidade de vida do paciente ${ }^{(6)}$.

Foram divididos três grupos entre as participantes do estudo para a coleta dos dados por entrevista e discussão grupal, conforme o Método Criativo Sensível proposto. A sessão de relaxamento com imaginação guiada teve duração de 15 minutos e foi realizada em uma sala reservada do ambulatório, onde as participantes ficaram sentadas em cadeiras confortáveis, com luz ambiente reduzida e ao som do CD de relaxamento com imaginação guiada, que foi reproduzido por um aparelho de som portátil.

Depois da sessão, a pesquisadora, que realizou treinamento prévio por meio de atividades de estudo e prática dentro de seu grupo de pesquisa, conduziu a entrevista fenomenológica mediante um formulário não estruturado, em que as participantes foram indagadas, em grupo, acerca das seguintes questões norteadoras: 1 - Como você visualiza sua doença?; 2 - Como você visualiza seu sistema imunológico?; 3 - Como você se sente após o relaxamento com visualização guiada? Todos os relatos foram audiogravados e, posteriormente, transcritos.

\section{ANÁlISE E TRATAMENTO DOS DADOS}

As entrevistas transcritas foram submetidas à leitura preliminar, com a finalidade de organizar as ideias, retomar os objetivos iniciais da pesquisa e elaborar indicadores que orientaram a interpretação desses dados. Foi utilizado, também, um diário de campo para o registro das expressões não verbais e das diversas outras formas de linguagem das participantes do estudo. O registro das expressões no diário de campo faz parte da entrevista fenomenológica, ao passo que elas, dentro da perspectiva comunicacional, são um sistema de códigos produzidos pela percepção do participante ao tomar consciência do fenômeno, podendo ser observados e interpretados pelo referencial adotado em meio ao processo de análise do significado atribuído a eles pelo sujeito em associação ao seu discurso.

Para a análise dos dados, posteriormente, foi utilizada a compreensão heideggeriana, que ocorreu em duas etapas: a compreensão vaga e mediana, que busca compreender aquilo que se mostra diretamente, ou seja, as estruturas essenciais do fenômeno estudado que emergem dos próprios depoimentos; e a hermenêutica, que busca desvelar o fenômeno por meio da interpretação dos sentidos atribuídos pelas participantes ${ }^{(13,15)}$.

A compreensão vaga e mediana, primeiro momento analítico heideggeriano, foi realizada por meio da escuta e leitura atenta dos depoimentos, onde foram encontrados os destaques dos significados ali contidos, mediante a historiografia e historicidade. A historiografia emergiu da dimensão ôntica do ser em estudo, quando se investigou a idade, situação conjugal, número de filhos, ocupação profissional, diagnóstico, realização de cirurgia prévia e tratamento oncológico. Já na historicidade, buscou-se a análise da dimensão fenomenal das vivências das participantes, quando a subjetividade 
expressa nos depoimentos e no encontro em grupo realizado mostrou-se o foco da análise ${ }^{(13,15)}$

Para a busca das unidades de significados, foi realizada uma codificação para destacar as expressões do ser-aí das mulheres com câncer. Foram destacados, de diferentes formas dos depoimentos, os pronomes que indicavam quando as participantes falavam de si, de suas relações, de suas atividades cotidianas, dentre outras estruturas essenciais. Em seguida, realizou-se a hermenêutica para a compreensão interpretativa dos sentidos identificados na dimensão do fenômeno ${ }^{(13,15)}$. Com isso, as três unidades de significado identificadas emergiram das estruturas essenciais que desvelaram os sentidos do fenômeno estudado nos depoimentos das participantes. Tais unidades foram construídas, após a análise proposta, pela expressão das similaridades e interseção dos significados elucidados fenomenologicamente.

\section{ASPECTOS ÉTIICOS}

Este estudo foi aprovado pelo Comitê de Ética em Pesquisa da Escola de Enfermagem de Ribeirão Preto da Universidade de São Paulo, sob o parecer número 1.411.384, e pelo Comitê de Ética e Pesquisa da instituição coparticipante, em 16 de fevereiro de 2016, atendendo à Resolução 466/12, do Conselho Nacional de Saúde. A pesquisadora apresentou o objetivo da pesquisa, o Termo de Consentimento Livre e Esclarecido (TCLE) às participantes, que, ao concordarem em participar da pesquisa, realizaram a formalização do aceite por meio da assinatura do TCLE. Com o intuito de garantir o anonimato das entrevistadas optou-se pelo uso do nome de flores, escolhidas pelas próprias depoentes, acompanhado pelo número da entrevista e do grupo realizado para a identificação das suas falas.

\section{RESULTADOS}

Participaram deste estudo nove mulheres com câncer de mama em tratamento radioterápico, que foram convidadas a participar da pesquisa por conveniência e divididas em três grupos para realizar uma sessão de relaxamento com imaginação guiada, bem como a dinâmica de sensibilidade e criatividade para a sensibilização delas diante de suas percepções a respeito da terapia.

De modo a melhorar a compreensão das entrevistas, voltamos o olhar, também, para os dados sociodemográficos e clínicos das participantes: a idade das entrevistadas variou de 45 a 67 anos; cinco participantes foram submetidas à cirurgia de mastectomia de uma das mamas e quatro de quadrantectomia. Três participantes realizaram o esvaziamento axilar, e oito o tratamento quimioterápico. A maioria declarou-se católica (sete), seis eram casadas, duas solteiras, e uma viúva. Três eram aposentadas, duas desenvolviam atividades formais remuneradas, e quatro eram do lar. Quanto ao número de filhos, duas participantes declararam não possuir nenhum filho, quatro apenas um filho, e três dois filhos.
A compreensão dos dados advindos das entrevistas permitiu apreender o significado do relaxamento com imaginação guiada pelas participantes à luz de seu movimento existencial, que puderam ser classificados em três unidades de significado: o estigma do câncer, o enfrentar da doença e os benefícios do tratamento.

\section{O ESTIGMA DO CÂNCER}

Sabe-se que o câncer é uma doença que carrega muitos estigmas, crenças e temores relacionados ao tratamento e às perspectivas de vida diante da doença, o que influencia significativamente o modo pelo qual o indivíduo o enfrenta. $\mathrm{O}$ modo como as participantes construíram suas narrativas sobre a doença mostraram a forma pela qual a enfrentaram e suas experiências pessoais a respeito. Pode-se notar que algumas das mulheres deste estudo não gostavam de visualizar a imagem do câncer em seu corpo, quando solicitado durante o relaxamento com imaginação guiada, e que, até mesmo, preferiam não o imaginar.

Eu imaginei assim... porque, quando você descobre, Santo Deus, é um horror! Mas, depois... eu imaginei assim, já tirou de mim, não me pertence mais, vou viver. Não tenho mais nada! (Tulipa4 - Grupo 2).

Em momento algum eu visualizo uma ferida. Não vejo nada de ferida! Não vejo nada de doença! Eu falo que não tenho mais nada e, aí, eu penso só em coisa boa, só visualizo coisa boa... como ramagens (Jasmim8 - Grupo 3).

As manifestações das participantes diante da visualização da doença em seu corpo mostram os seus modos e maneiras de expressão do ser mulher e suas relações com o mundo. A existência é dada, por vezes, pela projeção de um mundo histórica e culturalmente criado em sua vida, onde, no caso da mulher, as questões corporais e de gênero são muito fortes. Além disso, o ser-com é dado, por vezes, como uma característica existencial da presença, já que o corpo é visto como uma condição intrínseca a esta pelas mulheres pesquisadas.

Durante o enfrentamento da doença, a mulher encontra-se com si mesma e confronta-se com o outro, ou seja, tudo aquilo que se espera dela como ser no mundo, o que torna ainda mais difícil lidar com a doença e seus sintomas. Muitas vezes, aquilo que é valorizado pela sociedade e que se espera da mulher, na situação do adoecimento, proporciona uma reflexão íntima do ser com os significados atribuídos a sua própria existência frente a seus sentimentos, esperanças, crenças, valores e vivências ${ }^{(13)}$.

$\mathrm{Na}$ dimensão do ser-para-o-outro, conforme Heidegger, nos damos conta de que vivemos com outras pessoas em sociedade, que, por sua vez, possui regras e preceitos de base ética para sua construção, onde tudo aquilo que se espera do outro é a certa realidade que se apresenta a nossa convivência. Diante da vivência do câncer de mama em sua vida, em especial, da solicitação de imaginação da doença em seu corpo pelo relaxamento, as mulheres são colocadas frente à oportunidade de romper com tal cadeia utilitária imposta ao ente, por meio da reflexão sobre o ser-com câncer enquanto experiência ${ }^{(13)}$. 
Vivenciar e refletir a respeito da doença permite que a paciente entre em contato consigo e se perceba durante esse processo. A imagem criada pela participante para representar o câncer em seu corpo, durante o relaxamento com imaginação guiada, evidencia o aumento da capacidade de imaginação dela durante a terapia, uma vez que ela busca aproximar a imagem da doença a sua realidade. Assim, a imagem da doença passa a ser ressignificada pela paciente, permitindo que ela reflita sobre suas próprias concepções acerca daquela vivência, bem como às das outras participantes do grupo.

Eu visualizei assim... Como um caroço de abacate, sabe? Algo que vai se partindo... Alguma coisa mais ou menos desse tipo. (...) Começou pequeno e foi crescendo... Foi assim que visualizei (Margarida1 - Grupo 1).

(...) Eu visualizo assim, como se fosse um grão de arroz, sabe? E esse meu arroz era bem pequeno... Era um grão de arroz! Mas cada um tem o grão do tamanho que quer, não é?... Então, o meu era bem pequeno! E uma coisa parada também... Eu conseguia ver uma coisa parada (...) (Girassol7 - Grupo 3).

A participante Hortênsia manteve-se emocionada durante a entrevista grupal, expressando seus sentimentos na seguinte fala:

Eu já imaginava antes. (...) Logo no início, eu vi os ultrassons e dava bem para visualizar... Depois, toda vez que fazia um ultrassom, eu fui vendo que com as quimio... é, eu fui vendo que ele foi diminuindo... foi diminuindo, diminuindo (...) Então, eu tenho ele muito nitido na minha cabeça... A imagem... Porque eu sempre via, sabe (...) (Hortênsia5 - Grupo 2).

\section{O enfrentar dA DOEnÇA}

Quanto à segunda unidade de significado encontrada, a partir da sessão de relaxamento com imaginação guiada, foi possível entender, também, como a mulher enfrenta o câncer e o processo de tratamento da doença. Os diferentes modos de enunciação das participantes permitiram nos aproximar do ser manifesto e abstrato por elas.

$\mathrm{O}$ sentimento de angústia profunda, que, segundo Heidegger, acontece quando nos damos conta de que estamos perdendo o nosso eu, nos faz despertar da existência inautêntica, que revela, frequentemente, como nos dissolvemos na impessoalidade cotidiana. De acordo com o autor, a angústia desvela-se no próprio vazio e é capaz de nos reconduzir ao nosso próprio encontro, como uma chance do resgate do ser-aí para a liberdade. E é a este processo que chamamos como o meio caminho entre o ser e o nada, onde, no caso do presente estudo, as mulheres recebem a possibilidade de não lutarem e fugirem para o esquecimento de sua dimensão profunda (o ser) e voltar ao cotidiano; ou, ainda, poderem manifestar o seu poder de transcendência sobre o mundo e si mesma, conseguindo, assim, lidar com o câncer e suas consequências físicas, psicológicas e emocionais ${ }^{(13)}$.

As participantes Cravo e Jasmim desvelaram, em seu discurso, como a mulher pode aceitar a doença e o acolhimento desta como parte de seu ser durante esse processo de enfrentamento:

(...) agora, parece que as coisas estão caminhando... Eu também estou percebendo que ofator emocional influencia muito, então, eu ainda preciso trabalhar mais essa parte para que nada me deixe estressada e não aconteça mais isso. Eu já aceitei! É meu... pronto, tá bom! Podia ser pior, né? (...) Sinto que isso me deu uma boa melhora (Cravo9-Grupo 3).

(...) Agora que eu estou mais fragilizada. Não sei se épelo tempo que passou ou por conta das dores que a gente sente, ou ainda, pelas limitações. Então, de um mês e meio para cá, que eu estou um pouquinho mais fragilizada... Psicologicamente, sabe?... Mas, eu acho que eu vou melhorar, porque eu nunca parei de trabalhar e vejo esse meu lado positivo, né (...) (Jasmim8-Grupo 3).

Cabe revelar, ainda, que é nesse caminho entre o ser e o nada que a mulher com câncer de mama se depara com a finitude da sua existência e a possibilidade de superá-la, realizando plenamente o seu ser. De acordo com este autor, a maioria das pessoas compreende a morte apenas em seu sentido trivial, sendo o pensar nesta um sinal de insegurança mórbida e de inadequação patológica por parte do Dasein, termo utilizado por Heidegger em sua obra Ser e tempo ${ }^{(13)}$, com o significado de estar-aí ou ser-no-mundo, o qual indica a presença e o modo de ser em sua cotidianidade.

Assim, diante da angústia, a mulher com câncer de mama passa a precisar administrar a consciência de que é mortal. Em outras palavras, o adoecer por câncer de mama revela à mulher o pensamento do ser-para-a-morte, outra dimensão do ser estudada pelo autor, já que o câncer é muito reconhecido por seus estigmas de doença grave e que antecede o ser à morte. Frente à busca pela compreensão ontológica de finitude, portanto, o ser-para-a-morte torna-se, em essência, angústia, que acaba promovendo a aceitação da terminalidade existencial como condição absoluta da liberdade humana ${ }^{(13)}$.

Menina, eu fiquei tão abalada... Mas, vamos ver o que Deus quer dar, né? Não há pessoa que não se abale! Eu só pensava em Deus nesse momento (...) (Violeta3 - Grupo 1).

Eu imaginei como se fosse Jesus, que tirava tudo de mim... Um pano branco, sabe?... Foi o que eu imaginei, como se fosse Jesus (...) Muito bom! (Rosa2 - Grupo 1).

É interessante verificar como as imagens do sistema imunológico combatendo o câncer, durante a sessão de relaxamento, seguiram um caráter religioso e de representação das crenças e experiências de vida das participantes.

Eu vi um monte de anjos combatendo... Todos vestidos de branco, sabe? Aquelas crianças... tá relacionado a minha própria profissão e um monte de mais coisas... sou professora (...) Mas, vi como anjos mesmo combatendo, né. (...) as crianças são anjos! Gostei! (Hortênsia5 - Grupo 2).

Em termos da analítica existencial, a própria existência é a fundamental essência de todo o Dasein, não cabendo, assim, explicações de cunho religioso para a referência ao ser, já que isto o toma como ente. A religião precisa fazer parte de uma análise da realidade factual das participantes, ou seja, do 
fenômeno histórico ao qual pertencem ${ }^{(13)}$. Entretanto, diante da incerteza futura, desvelada pelas mulheres do presente estudo, a fé e a esperança revelam-se como virtudes pactuadas do impossível. O Deus do impossível, presente nos mais diversos relatos bíblicos e de milagres, coloca o ser diante da ideia do futuro absoluto, ressaltando a esperança da resolutividade do que não se tem domínio, como no caso do câncer.

O relaxamento com imaginação guiada, no presente estudo, mostrou-se como um interessante auxílio para a sensibilização da capacidade das participantes em imaginar seu sistema imunológico combatendo a doença, sendo, este, também, associado a uma série de ações fisiológicas que ajudam a participante neste enfrentamento.

(...) Quando é para visualizar só ele, eu vejo um monte de soldadinhos de branco... igual um monte de japonês. Samuraizinhos, sabe? Tudo de branco! (...) Ai, quando eles vão fazer as coisas, eles usam um escudo todo dourado, que, quando eles se juntam, eu vejo tudo dourado... No começo, o dourado está na cabeça e vai vendo tudo o que eu tenho... até lá no final, né. (...) Dai, quando está tudo dourado, eu jogo tudo fora... Eles guardam os escudos e ficam todos de branco de novo (...) (Girassol7 - Grupo 3).

\section{OS benefí́CIOS Do TRATAMENTO}

Dessa forma, a reflexão sobre o ser e o aumento da capacidade de imaginação pelas participantes provocada pela terapia evidencia como o relaxamento pode ser utilizado como uma estratégia direta e poderosamente terapêutica para o enfrentamento da doença e tratamento.

Nesse sentido, a terceira unidade de significado encontrada mostrou que essa prática de relaxamento melhora a qualidade de vida dos pacientes durante o tratamento. As participantes do presente estudo relataram a sensação de leveza, bem-estar e relaxamento físico e mental após as sessões de relaxamento com imaginação guiada.

É bom! Eu estava bem tensa... então ajudou bastante, deu uma relaxada. Eu ando bem tensa, sabe? Então ajudou. Gostei! (Margarida1-Grupo1).

(...) Eu fui lá no meu riozinho... onde eu nasci, sabe? Em um sítio. Parece que eu estava vendo até a cor da água... sentada, em uma pedra no rio. Me senti bem e aliviada. Parece que o corpo está leve. (...) Eu amei, viu? (Lírio6 - Grupo2).

A oportunidade de se avizinhar do ser por meio da reflexão proporciona a sensação de superioridade da angústia. $\mathrm{O}$ encontro com o eu é um movimento em busca da essência do fenômeno, e as experiências são entrelaçadas a lembranças positivas da manifestação do ente, o engate do desvelar do modo de ser/estar-aí no mundo das participantes ${ }^{(13)}$.

\section{DISCUSSÃO}

Os dados sociodemográficos e clínicos das participantes vão ao encontro da literatura, em que se verificou uma associação significante entre a prática da terapia e as variáveis sociodemográficas e clínicas analisadas ${ }^{(16-17)}$. Cabe ressaltar que outros fatores também são frequentemente associados ao uso da terapia, como a presença de sintomas de dor, fadiga, ansiedade, depressão e náuseas e vômitos ${ }^{(3,16-17)}$.
Em relação ao estigma do câncer, autores ${ }^{(18)}$ mostraram em seu estudo que a imagem corporal e a sexualidade de mulheres com câncer de mama são "parte de um importante processo de reformulação da imagem corporal" como consequência do tratamento da doença. Esse estudo evidenciou que as "mulheres submetidas à mastectomia radical sem reconstrução da mama apresentaram maiores índices de insatisfação com a própria imagem corporal", além de mostrar maior preocupação com sua aparência física, fatores estes atribuídos a "múltiplos aspectos de ordem física, psicológica e social que se fazem presentes na reelaboração da imagem corporal feminina"(18).

A negação da doença constitui-se em uma fase temporária para a mulher, sendo, posteriormente, substituída pela aceitação parcial do câncer e seu tratamento. Um estudo mostrou, inclusive, que o sentido da descoberta do nódulo de mama para a mulher mais jovem é diferente do significado da doença para a mulher mais velha, já que a mulher jovem demora a tomar consciência da condição de estar com câncer por não estar na idade considerada de risco para a doença ${ }^{(19)}$.

Quanto ao enfretamento da doença pela religiosidade, esse mesmo estudo vai ao encontro dos resultados desta pesquisa, mostrando que mulheres com câncer de mama utilizaram a religião como recurso para o manejo das situações estressantes vivenciadas, bem como a ação de outorgar a Deus a responsabilidade de solucionar tais eventos ${ }^{(19)}$. Um outro estudo, sobre o uso de terapias complementares e espirituais por pacientes oncológicos mostrou que muitos deles utilizam-nas em busca de espaços terapêuticos para compartilhar a experiência e sentimentos com relação à doença ${ }^{(20)}$.

Uma revisão sistemática da literatura sobre o coping religioso/espiritual e o câncer de mama revelou a grande relevância da espiritualidade e religiosidade para o defrontar da crise pelas mulheres ${ }^{(21)}$. O enfrentamento do câncer, no que diz respeito à religiosidade e espiritualidade, também foi investigado em uma revisão integrativa, que evidenciou o quanto o enfermeiro foi reconhecido por envolver-se, dentre os profissionais de saúde, com a temática em meio à pesquisa e assistência integral à saúde, sendo seu plano de cuidados e assistência mais integral aos pacientes ${ }^{(22)}$.

A busca pelo cuidado para tratar a doença também é um problema encontrado pelas mulheres durante seu enfrentamento, já que um estudo mostrou que há dificuldades, relatadas por elas, de acesso aos recursos disponíveis nos serviços públicos de saúde devido à grande demanda de atendimento ${ }^{(19)}$. As práticas integrativas e complementares são ofertadas pelo SUS, mas ainda há adversidades a serem superadas quanto ao acesso, estruturação, formação profissional, aceitação pelos usuários, registro de informações e ampliação do conhecimento científico a respeito ${ }^{(23-24)}$.

Nessa busca pelo conhecimento científico a respeito dos benefícios do tratamento, a literatura da área mostra que as imagens guiadas produzem respostas psicológicas que atingem o eixo hipotalâmico, o que resulta em uma diminuição do estresse, sensação de bem-estar e uma adaptação imunológica ${ }^{(6,25)}$. Assim, a capacidade de a mulher imaginar seu sistema imunológico combatendo o câncer é fundamental durante o relaxamento guiado, pois provoca uma série de ações fisiológicas que a auxiliam a enfrentar a doença ${ }^{(20)}$. 
Um estudo na área também mostrou que, após as sessões de relaxamento, os participantes estavam mais dispostos e comunicativos, com sentimentos de bem-estar e pensamentos mais positivos quanto à vida ${ }^{(25)}$. Contudo, ressalta-se certa limitação na literatura sobre tais achados, pois não há estudos com nível de evidência científica forte que comprovem e descrevam como ocorrem tais processos fisiológicos, o que nos mostra, também, a grande necessidade e importância do desenvolvimento de pesquisas clínicas randomizadas para a construção do conhecimento científico na área, com maiores níveis de evidências.

Além disso, embora a presente amostra tenha sido capaz de responder às questões investigadas no estudo, considera-se como limitação a ampla generalização dos resultados apresentados, fator este relacionado à própria ótica existencialista, em que o significado não pode ser dado como algo acabado para o estudo. A dimensão existencial é, pois, muito complexa e desafiadora para a pesquisa, sendo os fenômenos modificados a cada olhar e jamais esgotados em apenas uma perspectiva. Pode-se afirmar, porém, que a terapia de relaxamento com imaginação guiada permitiu desvelar o significado do Dasein com câncer de mama das mulheres investigadas, sendo esta uma terapia reflexiva, benéfica e de potencial adesão como tratamento complementar durante essa experiência.

\section{CONCLUSÃO}

Os relatos desvelaram o significado da terapia do relaxamento com imaginação guiada para as mulheres com câncer de mama em tratamento radioterápico. A análise e interpretação das vivências manifestadas pelos discursos das participantes permitiram a compreensão do fenômeno, bem como os seus modos de ser/estar-aí no mundo. Assim, foi oportunizado o surgimento de um novo olhar para o cuidado de enfermagem frente à situação factual do vivenciar o câncer e o processo de enfrentamento e tratamento da doença. O estudo mostrou que, por meio da compreensão do fenômeno, o oferecimento da terapia de relaxamento nos cuidados à mulher com câncer de mama possibilita o encontro do ser-no-mundo durante as reflexões proporcionadas pela terapia.

\section{RESUMO}

Objetivo: Compreender o significado do relaxamento com imaginação guiada para mulheres com câncer de mama, buscando investigar, também, como as pacientes visualizam o câncer e seu sistema imunológico durante as sessões de relaxamento com imaginação guiada e se sentem após sua realização. Método: Estudo de natureza qualitativa, com abordagem fenomenológica e referencial teóricometodológico heideggeriano, fundamentado no Método Criativo e Sensível, desenvolvido no ambulatório de radioterapia de um hospital de ensino público do interior paulista. Para a análise dos dados foi utilizada a compreensão heideggeriana, que ocorreu em duas etapas: a compreensão vaga e mediana e a hermenêutica. Resultados: Participaram do estudo nove mulheres com idade entre 45 e 67 anos. Os dados permitiram compreender o significado do relaxamento com imaginação guiada pelas participantes, pois puderam ser classificados em três unidades de significado: o estigma do câncer, o enfrentar da doença e os benefícios do tratamento. Conclusão: O significado do relaxamento com imaginação guiada possibilitou a compreensão do ser-no-mundo durante as reflexões proporcionadas, sendo possível verificar a importância do oferecimento da terapia pelo enfermeiro nos cuidados da mulher com câncer de mama.

\section{DESCRITORES}

Neoplasias da Mama; Terapia de Relaxamento; Terapias Complementares; Enfermagem Oncológica; Saúde da Mulher.

\section{RESUMEN}

Objetivo: Comprender el significado de la relajación con imaginación guiada para mujeres con cáncer de mama, tratando de investigar asimismo cómo las pacientes visualizan el cáncer y su sistema inmunológico durante las sesiones de relajación con imaginación guiada y se sienten después de su realización. Método: Estudio de naturaleza cualitativa, con abordaje fenomenológico y marco de referencia teórico metodológico heideggeriano, fundado en el Método Creativo y Sensible, desarrollado en el ambulatorio de radioterapia de un hospital de enseñanza pública del interior del Estado de São Paulo. Para el análisis de los datos fue utilizada la comprensión heideggeriana, que ocurrió en dos etapas: la comprensión vaga y mediana y la hermenéutica. Resultados: Participaron en el estudio nueve mujeres con edades entre 45 y 67 años. Los datos permitieron comprender el significado de la relajación con imaginación guiada por las participantes, pues pudieron clasificarse en tres unidades de significado: el estigma del cáncer, el enfrentamiento de la enfermedad y los beneficios del tratamiento. Conclusión: El significado de la relajación con imaginación guiada posibilitó la comprensión del ser-en-el-mundo durante las reflexiones proporcionadas, siendo posible verificar la importancia del ofrecimiento de la terapia por el enfermero en los cuidados a la mujer con cáncer de mama.

\section{DESCRIPTORES}

Neoplasias de la Mama; Terapia por Relajación; Terapias Complementarias; Enfermería Oncológica; Salud de la Mujer.

\section{REFERÊNCIAS}

1. World Health Organization. Cancer: key facts [Internet]. Geneva: WHO; 2018 [cited 2018 Jan 21]. Available from: https://www.who.int/ news-room/fact-sheets/detail/cancer

2. Brasil. Ministério da Saúde; Instituto Nacional de Câncer José Alencar Gomes da Silva. Estimativa 2018: incidência de câncer no Brasil [Internet]. Rio de Janeiro: INCA; 2017 [citado 2018 jan. 21]. Disponível em: http://www1.inca.gov.br/inca/Arquivos/estimativa-2018.pdf

3. Bahall M. Prevalence, patterns, and perceived value of complementary and alternative medicine among cancer patients: a cross-sectional, descriptive study. BMC Complement Altern Med [Internet]. 2017 [cited 2018 Feb 10];17:345. Available from: https://www.ncbi.nlm.nih. gov/pmc/articles/PMC5493839/

4. Tao WW, Jiang H, Tao XM, Jiang P, Sha LY, Sun XC. Effects of acupuncture, Tuina, Tai Chi, Qigong, and traditional Chinese medicine five-element music therapy on symptom management and quality of life for cancer patients: a meta-analysis. J Pain Symptom Manage. 2016;51(4):728-47. DOI: 10.1016/j.jpainsymman.2015.11.027 
5. Costa AIS, Reis PED. Complementary techniques to control cancer symptoms. Rev Dor [Internet]. 2014 [cited 2018 Mar 16];15(1):61-4. Available from: http://www.scielo.br/pdf/rdor/v15n1/en_1806-0013-rdor-15-01-0061.pdf

6. Nicolussi AC, Sawada NO, Cardozo FMC, Paula JM. Relaxation with guided imagery and depression in patients with cancer undergoing chemotherapy. Cogitare Enferm [Internet]. 2016 [cited 2018 Mar 16];21(4):1-10. Available from: http://docs.bvsalud.org/ biblioref/2017/04/833107/48208-191972-1-pb.pdf

7. Zhang M, Chan SW, You L, Wen Y, Peng L, Liu W, et al. The effectiveness of a self-efficacy-enhancing intervention for Chinese patients with colorectal cancer: a randomized controlled trial with 6-month follow up. Int J Nurs Stud. 2014;51(8):1083-92. DOI: http://dx.doi. org/10.1016/j. ijnurstu.2013.12.005

8. Brasil. Ministério da Saúde; Política Nacional de Práticas Integrativas e Complementares no SUS - PNPIC-SUS: atitude de ampliação de acesso [Internet]. 2a ed. Brasília; 2015 [citado 2018 fev. 7]. Disponível em: http://bvsms.saude.gov.br/bvs/publicacoes/politica_nacional_ praticas_integrativas_complementares_2ed.pdf.

9. Brasil. Ministério da Saúde. Portaria n. 849, de 27 de março de 2017. Inclui a Arteterapia, Ayurveda, Biodança, Dança Circular, Meditação, Musicoterapia, Naturopatia, Osteopatia, Quiropraxia, Reflexoterapia, Reiki, Shantala, Terapia Comunitária Integrativa e Yoga à Política Nacional de Práticas Integrativas e Complementares [Internet]. Brasília; 2017 [citado 2018 fev. 7]. Disponível em: http://bvsms.saude.gov. br/bvs/saudelegis/gm/2017/prt0849_28_03_2017.html

10. Brasil. Ministério da Saúde. Portaria n. 702, de 21 de março de 2018. Altera a Portaria de Consolidação nº 2/GM/MS, de 28 de setembro de 2017, para incluir novas práticas na Política Nacional de Práticas Integrativas e Complementares - PNPIC [Internet]. Brasília; 2018 [citado 2018 abr. 12]. Disponível em: http://bvsms.saude.gov.br/bvs/saudelegis/gm/2018/prt0702_22_03_2018.html

11. Conselho Federal de Enfermagem. Resolução COFEN n. 0500/2015. Dispõe sobre o estabelecimento e reconhecimento de Terapias Alternativas como especialidade e/ou qualificação do profissional de Enfermagem e dá outras providências [Internet]. Brasília; 2015 [citado 2018 fev. 28]. Disponível em: http://www.cofen.gov.br/resolucao-cofen-no-05002015_36848.html.

12. Pereira RDM, Alvim NAT. Acupunture to intervence in nursing diagnosis: assessment of nursing experts. Esc Anna Nery [Internet]. 2016 [cited 2018 May 7];20(4):e20160084. Available from: http://www.scielo.br/pdf/ean/v20n4/en_1414-8145-ean-20-04-20160084.pdf

13. Heidegger M. Ser e tempo. $10^{\mathrm{a}}$ ed. Petrópolis: Vozes; 2015.

14. Bergold LB, Alvim NAT, Cabral IE. O lugar da música no espaço do cuidado terapêutico: sensibilizando enfermeiros com a dinâmica musical. Texto Contexto Enferm [Internet]. 2006 [citado 2018 maio 22];15(2):262-9. Disponível em: http://www.scielo.br/pdf/tce/v15n2/a09v15n2.pdf

15. Reticena KO, Beuter M, Sales CA. Life experiences of elderly with cancer pain: the existencial comprehensive approach. Rev Esc Enferm USP [Internet]. 2015 [cited 2018 Mar 2];49(3):417-23. Available from: http://www.scielo.br/scielo.php?script=sci_arttext\&pid $=$ S0080-62342015000300417

16. Kim YH, Kim HJ, Ahn SD, Seo YJ, Kim SH. Effects of meditation on anxiety, depression, fatigue and quality of life of women undergoing radiation therapy for breast cancer. Complement Ther Med. 2013;21(4):379-87. DOI: http://dx.doi.org/10.1016/j.ctim.2013.06.005

17. Ferreira VTK, Prado MAS, Panobianco MS, Gozzo TO, Almeida AM. Characterization of pain in women after breast cancer treatment. Esc Anna Nery [Internet]. 2014 [cited 2018 Apr 16];18(1):107-11. Available from: http://www.scielo.br/pdf/ean/v18n1/en_1414-8145ean-18-01-0107.pdf

18. Santos DB, Vieira EM. Imagem corporal de mulheres com câncer de mama: uma revisão sistemática da literatura. Ciênc Saúde Coletiva [Internet]. 2011 [cited 2018 abr. 16]; 16(5):2511-2522. Available from: https://scielosp.org/pdf/csc/2011.v16n5/2511-2522/pt

19. Almeida TG, Comassetto I, Alves KMC, Santos AAP, Silva JMO, Trezza MCSF. Experience of young women with breast cancer and mastectomized. Esc Anna Nery [Internet]. 2015 [cited 2018 May 8];19(3):432-8. Available from: http://www.scielo.br/pdf/ean/v19n3/ en_1414-8145-ean-19-03-0432.pdf

20. Aureliano WA. Terapias espirituais e complementares no tratamento do câncer: a experiência de pacientes oncológicos em Florianópolis (SC). Cad Saúde Colet [Internet]. 2013 [citado 2018 abr. 6];21(1):18-24. Disponível em: http://www.scielo.br/pdf/cadsc/v21n1/a04.pdf

21. Veit CM, Castro EK. Coping religioso/spiritual e câncer de mama: uma revisão sistemática da literatura. Psicol Saúde Doenças [Internet]. 2013 [citado 2018 maio 8];14(1):1-22. Disponível em: http://www.scielo.mec.pt/pdf/psd/v14n1/v14n1a01.pdf

22. Sousa FFPRD, Freitas SMFM, Farias AGS, Cunha MCSO, Araújo MFM, Veras VS. Religious/Spiritual coping by people with cancer undergoing chemotherapy: integrative literature review. SMAD Rev Eletr Saúde Mental Álcool Droga [Internet]. 2017 [cited 2018 Apr 19];13(1):45-51. Available from: http://pepsic.bvsalud.org/pdf/smad/v13n1/07.pdf

23. Telesi Júnior E. Práticas integrativas e complementares em saúde, uma nova eficácia para o SUS. Estud Av [Internet]. 2016 [citado 2018 abr. 19];30(86):99-112. Disponível em: http://www.scielo.br/pdf/ea/v30n86/0103-4014-ea-30-86-00099.pdf

24. Lima KMSV, Silva KL, Tesser CD. Integrative and complementary practices and the relation to health promotion: the experience of a municipal healthcare service. Interface (Botucatu) [Internet]. 2014 [cited 2018 Apr 15];18(49):261-72. Available from: http://www.scielo. br/pdf/icse/v18n49/en_1807-5762-icse-1807-576220130133.pdf

25. Lufiego CA, Schineider RH, Bós AJG. Eficácia da técnica de relaxamento com imagem guiada em pacientes oncológicos submetidos a tratamento quimioterápico. Sci Med [Internet]. 2017 [citado 2018 abr. 19];27(1):ID25701. Disponível em: http://revistaseletronicas.pucrs. br/ojs/index.php/scientiamedica/article/view/25701/15435

Apoio financeiro

Fundação de Amparo à Pesquisa do Estado de São Paulo (FAPESP). Processo n. 2015/18103-6, Bolsa de Iniciação Científica. 
Errata - O significado de uma terapia integrativa de

relaxamento guiado para mulheres com câncer de mama

No artigo "O significado de uma terapia integrativa de relaxamento guiado para mulheres com câncer de mama", DOI: http://dx.doi.org/10.1590/S1980-220X2018024103497, publicado no periódico "Revista da Escola de Enfermagem da USP”, Volume 53 de 2019, elocation e03497, na página 1 e rodapés subsequentes:

Onde se lia:

Rev Esc Enferm USP. 2019;53:e03947

Leia-se:

Rev Esc Enferm USP. 2019;53:e03497 